\title{
Calcific uremic arteriolopathy Pathophysiology, reactive oxygen species and therapeutic approaches
}

\author{
Kurt M. Sowers ${ }^{1,2}$ and Melvin R. Hayden ${ }^{3-5, *}$
}

University of Maryland; Division of 'Nephrology; ${ }^{2}$ Physiology; University of Missouri School of Medicine; Departments of ${ }^{3}$ nnternal Medicine; ${ }^{4}$ Endocrinology Diabetes and Metabolism; ${ }^{5}$ Diabetes and Cardiovascular Disease Research Center; University of Missouri School of Medicine; Columbia, MI USA

Key words: calcific obliterative arteriolopathy, calciphylaxis, fetuin-A, inflammation, oxidative stress, sodium thiosulfate, ultrastructure, vascular calcification

\begin{abstract}
Abbreviations: CUA, calcific uremic arteriolopathy; CKD, chronic kidney disease; ESRD, end stage renal disease; VSMC, vascular smooth muscle cell(s); ROS, reactive oxygen species; MGP, matrix GLA protein; AHSG, alpha2-heremans-schmid

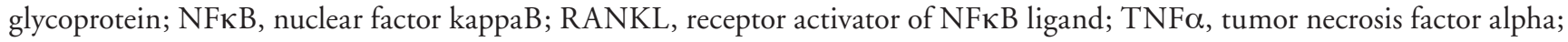
IL-1, interleukin-1; IL-6, interleukin-6; ET-1, endothelin-1; eNOS, endothelial nitric oxide synthase; NO, nitric oxide; LDL-C, low density lipoprotein-cholesterol; HDL-C, high density lipoprotein-cholesterol; NADPH, nicotinamide adenine dinucleotide phosphate reduced; ADMA, asymmetrical dimethyl arginine; TNF $\alpha$, tumor necrosis factor alpha; hsCRP, highly sensitive $\mathrm{C}$ reactive protein; NKF KDOQI, national kidney foundation kidney disease outcomes quality initiative; HBO, hyperbaric oxygen; iPTH, intact parathyroid hormone; PTX, parathyroidectomy; tPA, tissue plasminogen activator; STS, sodium thiosulfate; GSH, glutathione; $\mathrm{H}_{2} \mathrm{~S}$, hydrogen sulfide; MMPs, matrix metalloproteinases; EMP, endothelial microparticles
\end{abstract}

Calcific uremic arteriolopathy (CUA)/calciphylaxis is an important cause of morbidity and mortality in patients with chronic kidney disease requiring renal replacement. Once thought to be rare, it is being increasingly recognized and reported on a global scale. The uremic milieu predisposes to multiple metabolic toxicities including increased levels of reactive oxygen species and inflammation. Increased oxidative stress and inflammation promote this arteriolopathy by adversely affecting endothelial function resulting in a prothrombotic milieu and significant remodeling effects on vascular smooth muscle cells. These arteriolar pathological effects include intimal hyperplasia, inflammation, endovascular fibrosis and vascular smooth muscle cell apoptosis and differentiation into bone forming osteoblast-like cells resulting in medial calcification. Systemic factors promoting this vascular condition include elevated calcium, parathyroid hormone and hyperphosphatemia with consequent increases in the calcium $x$ phosphate product. The uremic milieu contributes to a marked increased in upstream reactive oxygen species-oxidative stress and subsequent downstream increased inflammation, in part, via activation of the nuclear transcription factor NFKB and associated downstream cytokine pathways. Consitutive anti-calcification proteins such as Fetuin-A and matrix GLA proteins and their signaling pathways may be decreased, which further contributes to medial vascular calcification. The resulting clinical entity is painful, debilitating and

${ }^{*}$ Correspondence to: Melvin R. Hayden; Email: mrh29@usmo.com Submitted: 01/21/10; Revised: 01/29/10; Accepted: 02/01/10 Previously published online:

www.landesbioscience.com/journals/oximed/article/11354 contributes to the excess morbidity and mortality associated with chronic kidney disease and end stage renal disease. These same histopathologic conditions also occur in patients without uremia and therefore, the term calcific obliterative arteriolopathy could be utilized in these conditions.

\section{Introduction}

Calcific uremic arteriolopathy (CUA), previously termed calciphylaxis, characteristically occurs in patients with chronic kidney disease (CKD), especially those nearing or at end stage renal disease (ESRD) with secondary hyperparathyroidism. ${ }^{1}$ However, CUA has been observed in patients with normal renal function and calcium/phosphate metabolism. ${ }^{2-4}$ Its etiology is multifactorial and its estimated prevalence is reported in up to $4 \%$ of patients on dialysis. ${ }^{5,6}$ Risk factors are multiple and include female gender, diabetes mellitus, hyperphosphatemia, CKD, ESRD, mineral and bone disorders, obesity, warfarin anticoagulation, Caucasian ethnicity and others (Table 1). . $^{6-14}$

The term calciphylaxis was originally coined by Hans Seyle in $1962 .{ }^{15}$ In this context, he created a rodent model of systemic and local soft-tissue calcification characterized by sensitizing factors such as parathyroid hormone, vitamin D or a diet high in calcium and phosphorus followed by challenging factors such as trauma, iron salts, egg albumin, polymycin and glucocorticoids. Through his pioneering work, Seyle laid the foundation for understanding this debilitating disease in humans, describing it as a rare complication of CKD and secondary hyperparathyroidism involving the dermis and vasculature. Subsequently, our 
Table 1. Risk factors for the development of CUA/calciphylaxis

1. Female gender ${ }^{*}(5,6,13,17,18,64)$

2. Diabetes mellitus ${ }^{*}(5,6,14,17,18,29,64)$

3. Hyperphosphatemia and concomitant calcium times phosphorus product $^{*}(5,6,13,18,51,64)$

4. Chronic Kidney Disease (CKD) - End Stage Renal Disease (ESRD) $(5,6,13,14,17,18,64)$

5. Hemo and peritoneal dialysis duration ${ }^{(6,13,14,17)}$

6. Secondary hyperparathyroidism - Increased parathyroid hormone $^{(5,6,13,14,17,18,51,64)}$

7. Caucasian ethnicity ${ }^{(5,6,14,17)}$

8. Obesity ${ }^{(5,6,13,14,18,51,64)}$

9. Hypoalbuminemia (malnutrition and weight loss) $(5,6,13,18,51,64)$

10. Protein $\mathrm{C}$ and/or $\mathrm{S}$ deficiency ${ }^{(5,64)}$

11. Elevated alkaline phosphatase ${ }^{(13,18,64)}$

12. Warfarin anticoagulation - inhibits vitamin $\mathrm{K}$ interfering with matrix GLA protein ${ }^{(5,18,64)}$

13. Use of calcium phosphate binders ${ }^{(5,18,64)}$

Asterisks indicate strongest factors identified in multivariate analysis. ${ }^{13}$

improved understanding of this complex clinical condition indicates that the calcific changes in the vascular and dermal layers of the skin involve a myriad of signaling and structural abnormalities. Indeed, these abnormalities include intimal hyperplasia, inflammation, obliterative endovascular fibrosis, arteriolar medial calcification, thrombotic cutaneous ischemia with necrotic dermal, subdermal and adipose tissue necrosis with skin ulceration, and an undeniable increase in morbidity and mortality (Figs. 1 and 2).

CUA/calciphylaxis has been increasingly reported in the literature over the past five years with new case reports or discussions published almost monthly. ${ }^{6}$ This may be attributed, in part, to the increasing prevalence of CKD and its association with the epidemic of obesity and the aging population in westernized societies. ${ }^{6,8,14}$ Increased clinical recognition of CUA may also be related to a better understanding of the pathophysiology and mode of presentation. In this context, it is important to note that up to $80 \%$ of the patients with CUA/calciphylaxis have a very short life span and frequently die because of infectious complications. ${ }^{1,6-14}$

\section{Clinical Presentation}

The initial presenting complaint is often that of a dull deep dermal pain with periods of neuritic-type dysesthesia associated with palpable subcutaneous masses or dermal plaques. The dermal changes are associated with erythema, violaceous mottling and livedo reticularis (Fig. 2A), which progress to blackened regions of eschar formation and eventually non-healing ulcerations (Fig. 3A and B). Skin lesions were initially felt to occur primarily on the lower limbs (acral or distal); however, these lesions seem to be increasingly reported to involve the more obese tissues of the abdomen, trunk, genital and inner thigh regions (proximal). The eschars are quite painful, with involvement of the subdermal arterioles and proximal regions, which are frequently associated with marked adiposity (Figs. 2B-D and 3). Once adiposubdermal fibrotic-thrombotic occlusion develops, the skin and the underlying subdermal layers become necrotic and ulcerated, subject to infection with an associated increase in morbidity and mortality from systemic infection-sepsis. This model of media calcified vasculature, intimal hyperplasia, endovascular fibrosis, inflammation and associated procoagulant milieu predisposes to fibrotic-thrombotic ischemia with ensuing necrosis (Figs. 1, 2B-D and 3). . $^{-14}$

Recent evidence suggests that this clinical entity is multifactorial and increasingly common in patients of Caucasian ethnicity and female gender. Additionally, there has been noted an association with the risk factors of hyperphosphatemia, high alkaline phosphatase, low serum albumin and elevated calcium $\mathrm{x}$ phosphate product even though normal or low calcium levels may be present at the time of diagnosis in patients with CUA/ calciphylaxis. ${ }^{13}$

\section{Histopathologic Diagnosis}

Although CUA is a clinical diagnosis, histological confirmation is suggested and remains the gold standard for definitive diagnosis. Biopsies have described the pathognomonic lesions of small arteries and arteriolar medial calcification (up to 600 micrometer) with intimal hyperplasia, inflammatory responses, endovascular fibrosis, associated panniculitis, extravascular calcium deposition, thrombosis and tissue necrosis (Figs. 1-3).5,6,9,12 This description has helped differentiate CUA from other similar vasculopathies that may be present in a variety of patient populations presenting with isolated medial arteriolar calcification. While medial vascular calcification itself may be an isolated finding endemic to patients with renal insufficiency, diabetes mellitus, and atherosclerotic peripheral vascular disease not consistent with CUA, intimal calcification is unique to the intimal atherosclerotic process.

\section{Pathogenesis}

CUA is associated with multiple histologic abnormalities that collectively result in medial calcific, pro-stenotic-fibrotic, proinflammatory and prothrombogenic arterioles compatible with a calcific obliterative arteriolopathy-vasculopathy (Fig. 2B-D). ${ }^{1,5-14}$ While vascular calcification was initially described as a mere passive degenerative process, the present understanding indicates that it is an active coordinated process similar to bone modeling osteogenesis and physicochemical deposition of mineral. ${ }^{4,5,13,16}$ The existing model for vascular calcification begins with differentiation of vascular smooth muscle cell(s) (VSMC) into chrondrocyte, osteoblast-like cellular phenotypes. ${ }^{16-18}$ This mechanism is initiated with the interaction of uremia [hyperphosphatemia, multiple uremic toxins, and reactive oxygen species (ROS)] and the decrease of local vascular calcification inhibitory proteins such as Matrix Gla protein (MGP) and the systemic globulin: fetuin-A-( $\alpha 2-$ Heremans-Schmid glycoprotein) AHSG (Fig. 4). 


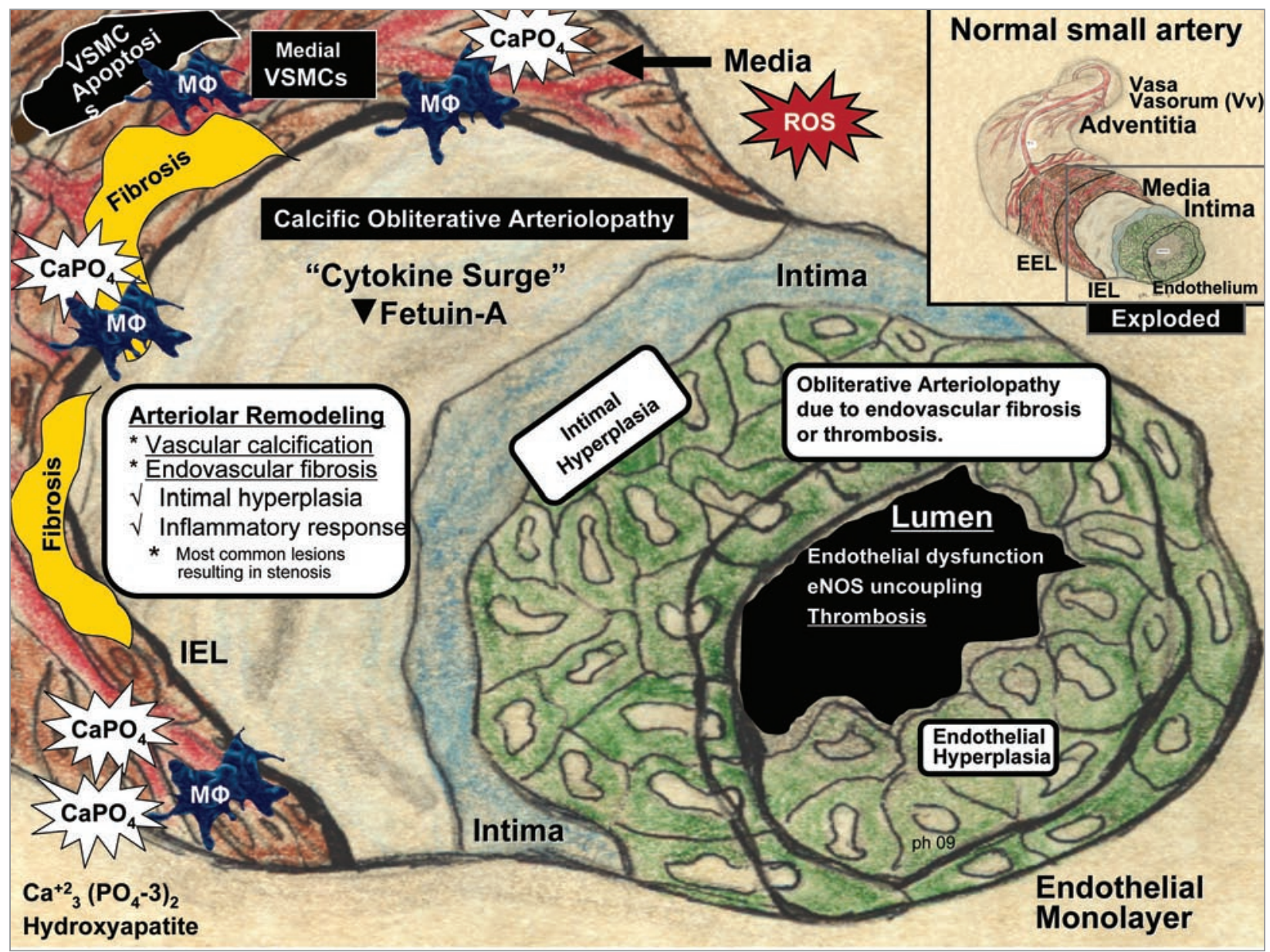

Figure 1. Arteriolar remodeling and vascular calcification in calcific uremic arteriolopathy (CUA)/calciphylaxis. Arteriole model depicted is derived from the pull out model of a normal small artery (upper right insert-boxed in area). This model demonstrates the four most common arteriolar findings observed in histologic sections in CUA/calciphylaxis: Vascular calcification, endovascular fibrosis, intimal hyperplasia, and inflammatory response. Intimal hyperplasia consists of the cellular expansion of the intima including endothelial hyperplasia (green). Excessive reactive oxygen species (ROS) due to uremic toxins may be the driving force promoting this calcific obliterative arteriolopathy due to either endovascular fibrosis or thrombosis. $\mathrm{Ca}$, calcium; EEL, external elastic lamina; eNOS, endothelial derived nitric oxide synthase; IEL, internal elastic lamina; $M \Phi$, macrophage; $P \mathrm{~A}^{\prime}$, phosphate; VSMC, vascular smooth muscle cell.

Bone morphogenic proteins belong to the transforming growth factor superfamily and are actively involved in inducing de novo bone formation/osteoclast differentiation and extraosseous calcification. ${ }^{16-19}$ Of note, this action is dependent on increased production of ROS, which are known activators of nuclear factor kappa B (NFKB). ${ }^{20}$ MGP, a vitamin K dependent localized protein, has been shown to inhibit bone morphogenic protein-2. Fetuin-A is a hepatic synthesized systemic inhibitor of hydroxyapatite formation (vascular calcification) and has been noted to be reduced in states of renal failure, inflammation, and in patients with CUA/calciphylaxis (Fig. 4)..$^{21,22}$

Chronic inflammatory states, including alcoholic steatohepatitis, insulin resistance and CKD/ESRD are associated with increased generation of $\mathrm{NF \kappa B}$ and receptor activator of $\mathrm{NF \kappa B}$ ligand (RANKL) suggesting that the NFKB-osteoprotegerin/ RANK/RANKL axis is an important system in bone homeostasis and vascular calcification (Fig. 4). ${ }^{23}$ In this regard, the aforementioned disease states are associated with obesity and altered adipocyte biology. Obesity is responsible for elevations in the detrimental cytokines-adipocytokines tumor necrosis factor alpha (TNF $\alpha$ ), interleukin-1 (IL-1) and interleukin-6 (IL-6) production. Obesity and the obesity epidemic may be the driving force behind the development of the cardiometabolic syndrome (insulin resistance), type 2 diabetes mellitus, cardiovascular disease, CKD, and increased oxidative stress-ROS. ${ }^{24,25}$ Obese subjects have higher fasting levels of oxidative stress biomarkers compared to non-obese subjects. Recently, it has been determined that obese females experienced significantly increased oxidative stress biomarkers (xanthine oxidase, malondialdehyde), $\mathrm{ROS}\left(\mathrm{H}_{2} \mathrm{O}_{2}\right)$, triglycerides, glucose and significantly lower antioxidant capacity in response to high fat meals that were sustained for longer time periods as compared to non-obese subjects. ${ }^{25}$ This increase in ROS could certainly be one of the mechanisms activating the upstream NFKB and subsequent downstream adipocytokinescytokines allowing further insight for potential mechanisms related to obesity-mediated morbidity. 

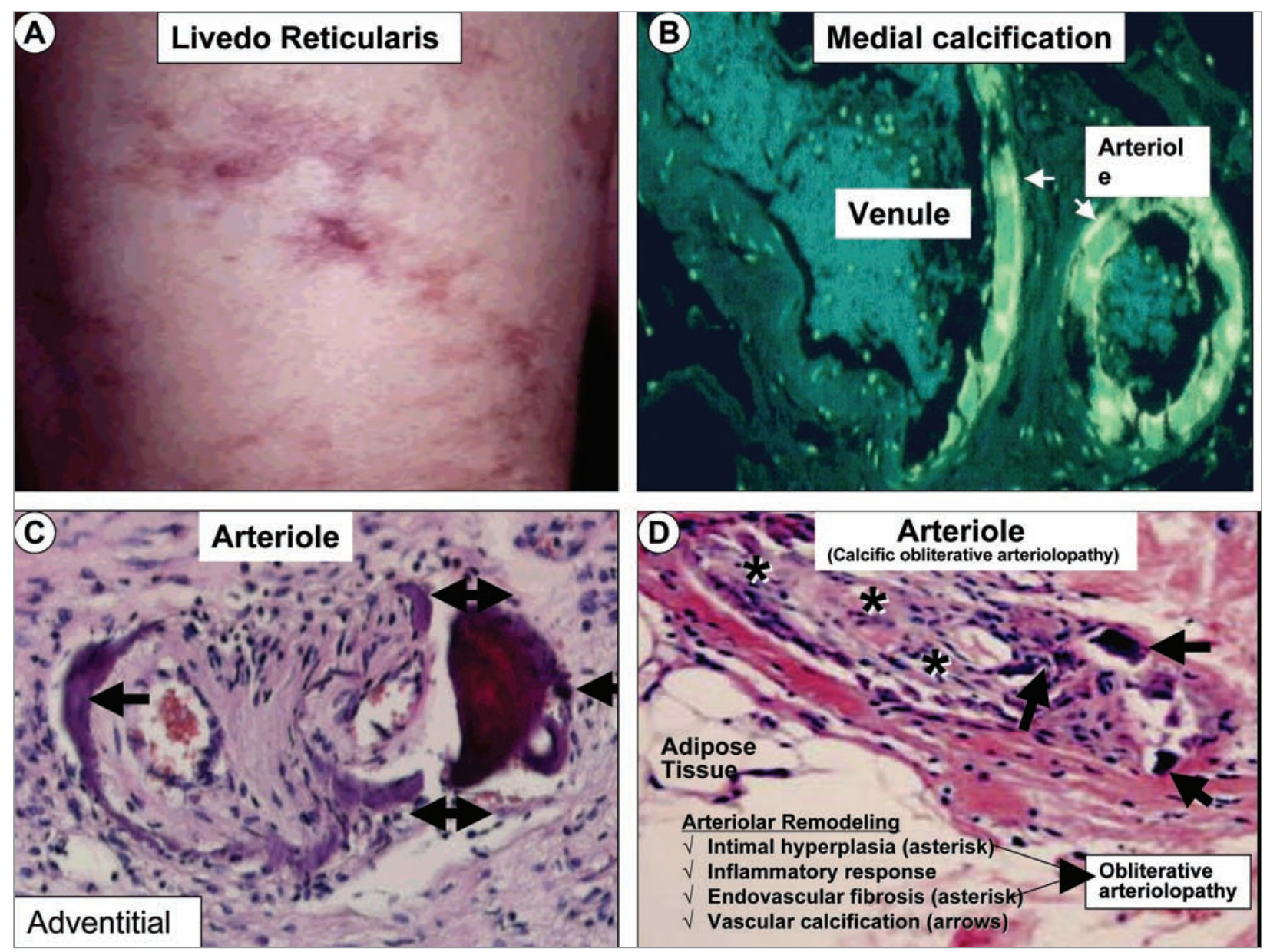

Figure 2. Early skin changes and histologic findings in calcific uremic arteriolopathy/calciphylaxis. (A) depicts the dermal changes of livedo reticularis (left anterior leg) prior to the initiation of hemodialysis. This image along with painful-palpable subcutaneous masses and plaques represent early skin changes associated with CUA/calciphylaxis. (B) is an inverted colorized hematoxylin and eosin (H\&E) stained image, which demonstrates medial calcification (arrows) in an arteriole and adjacent venule. This image is from biopsy of a breast mass one year prior to the development of CUA/calciphylaxis depicted in Figure 3. (C) portrays an outer adventitial location of vascular calcification (arrows) with H\&E staining. (D) depicts arteriolar remodeling including intimal hyperplasia, endovascular fibrosis (asterisks) and vascular calcification (arrows) resulting in calcific obliterative arteriolopathy with endothelial fibrosis and arteriolar obliteration. H \& E stain.

Importantly, the vasoconstrictor and vascular growth promoting substance endothelin-1 (ET-1) appears to be upregulated through the facilitation of the NFKB pathway in CUA, promoting VSMC calcification, vasoconstriction and loss of lumen diameter. ${ }^{26} \mathrm{TNF} \alpha$ and other cytokines elicit a hypercoagulable state through endothelial dysfunction with resultant release of tissue factor, reduced endothelial cell protein $\mathrm{C}$ and $\mathrm{S}$ receptor expression, decreased thrombomodulin expression, and ablation of natural vascular heparin-like molecules.

Following the reduction in the above described inhibitory molecules (MGP - fetuin-A) and accelerated ROS production, VSMC are more susceptible to morphologic differentiation and bone formation. Hyperphosphatemia is thought to be the triggering factor for the transition from the constitutive VSMC to osteoblast gene expression (osteogenic switch). The sodium/ phosphorus cotansporter (Pit-1) is the key protein involved in hydroxyapatite deposition and vascular calcification (Fig. 4).
Unfortunately, attempted management of hyperphosphatemia with calcium based phosphate binder's upregulates gene transcription of the cotransporter Pit- $1 .{ }^{27}$ Increased expression of the bone matrix protein osteopontin (an inducible inhibitor of vascular calcification), by immunostaining, has been identified in the VSMC of the calcified vasculature in human patients with CUA lesions and may predispose to sloughing of vascular cells into the vessel lumen contributing to arteriole obliteration even prior to arteriole thrombosis (Figs. 1 and 4). ${ }^{11,18,28}$

As previously noted, vascular calcification may precede the development of the skin changes and ulcerations associated with CUA/calciphylaxis. This important concept has resulted in the two stage concept set forth by Wilmer and Magro. ${ }^{29}$ Stage one is the development of the actual vascular lesion (period of sensitization induced by parathyroid hormone, vitamin $\mathrm{D}$ or high calcium and phosphorus) (Figs. 1 and 2). Stage two comprises the development of end-organ ischemia secondary to the expanding 

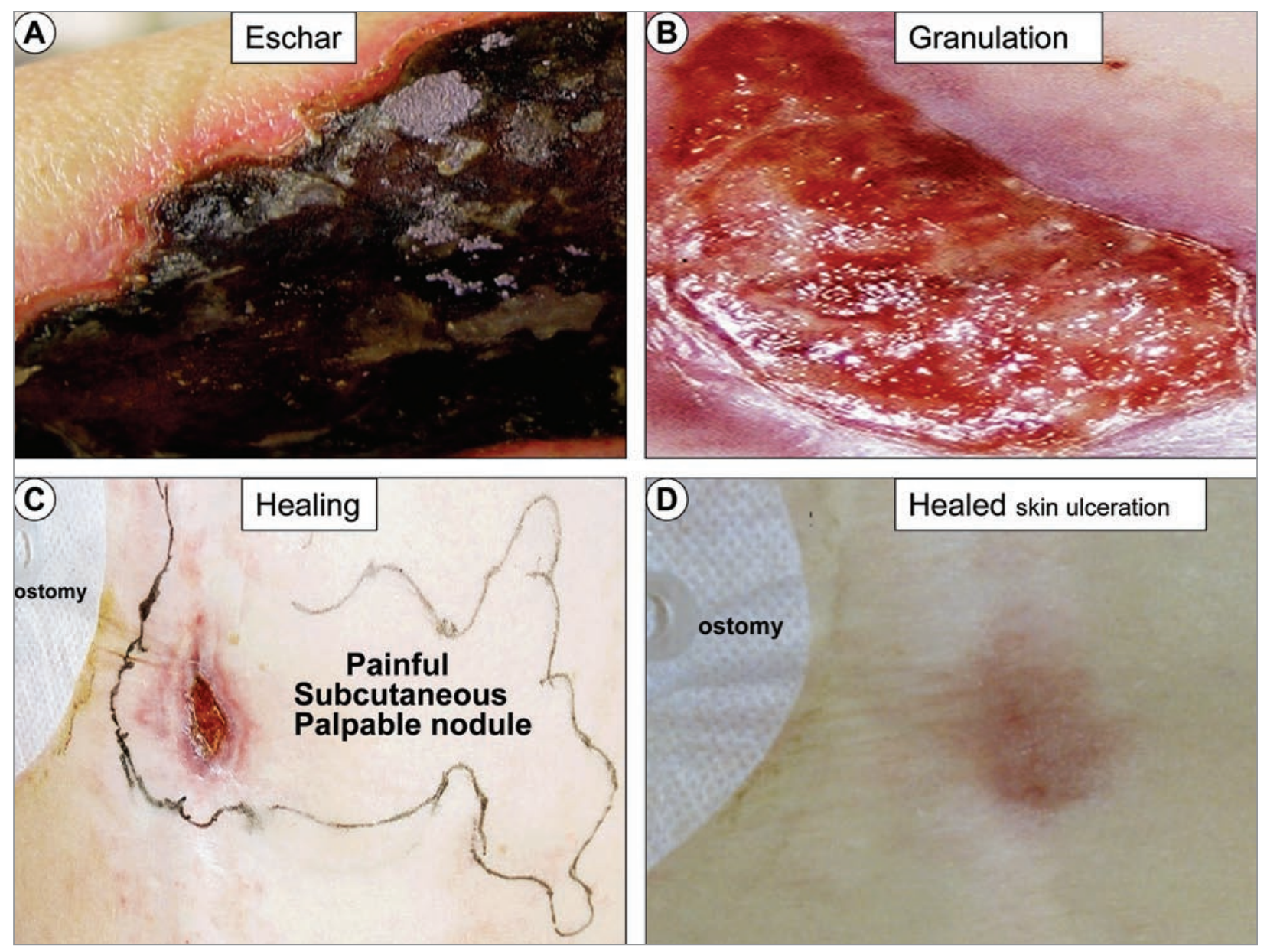

Figure 3. Intravenous sodium thiosulfate (STS) induced wound healing. Images of CUA eschar (A), clean granulating bed following two weeks of STS (B), healing phase (C) advancing to complete healing 3 months later in a 58 year old female treated with STS (D). Note the proximity of the skin ulceration to the patient's ileostomy and although this ulcer was small, it was highly vulnerable to infection and subsequent sepsis due to proximity to ileostomy. The large subcutaneous palpable nodule (C) was outlined demonstrating its relation to the skin ulceration $(\sim 7 \times 14 \mathrm{~cm})$ and gradually regressed after 4 months of STS treatment.

calcific vascular lesions now associated with obliterative endovascular fibrosis and/or vascular thrombosis (period of challenge such as trauma, surgery or any provoking inflammatory cytokine surge). These stages may be concurrent or be separated by months or years (Figs. 2 and 3). ${ }^{6,14,17,29}$

\section{Reactive Oxygen Species (ROS) in Pathogenesis of CUA/Calciphylaxis}

ROS are known to be important signaling molecules in health. However, excessive ROS are damaging to proteins, lipids, carbohydrates and nucleic acids, which prompt a classic "response to injury" mechanism including inflammation (both acute and chronic) supporting a cytokine surge, granulation and fibrosis. ${ }^{30-33}$ Figure 4 emphasizes the potential importance of ROS in the development of vascular calcification in CUA and demonstrates the salient relationship of the endothelium and VSMC in this pathological process. ROS are excessive, robustly produced in uremia, associated with multiple uremic toxins and the viscous cycle of the inflammatory cytokine surge, VSMC apoptosis, and endothelial dysfunction with endothelial nitric oxide synthase (eNOS) enzyme uncoupling resulting in decreased bioavailable endothelial derived nitric oxide (NO) (Figs. 4 and 5). ${ }^{17,30-33}$ Decreased bioavailable endothelial derived $\mathrm{NO}$ has a devastating effect on the small arteries and arterioles resulting in a proinflammatory, proconstrictive and prothrombotic vasculature, which may contribute significantly to the development of CUA/calciphylaxis and end-organ skin ulceration (Figs. 4 and 5).

Hyperglycemia, hyperhomocysteinemia, elevated $\beta-2$ microglobulin in uremia, elevated oxidized low density lipoproteincholesterol (LDL-C), and low levels of antioxidant high density lipoprotein-cholesterol (HDL-C) in atherogenic dyslipidemia are additional factors that may increase ROS and contribute to vascular calcification. ${ }^{31-33}$ In addition to endothelial NOS uncoupling (Fig. 5), there are other mechanisms that contribute to reduced bioavailable NO. For example, non-phagocytic nicotinamide adenine dinucleotide phosphate reduced (NADPH) oxidase enzyme due to activation by increased local levels of angiotensin II and aldosterone via their respective angiotensin type 1 and mineralocorticoid receptors result in increased ROS production. 


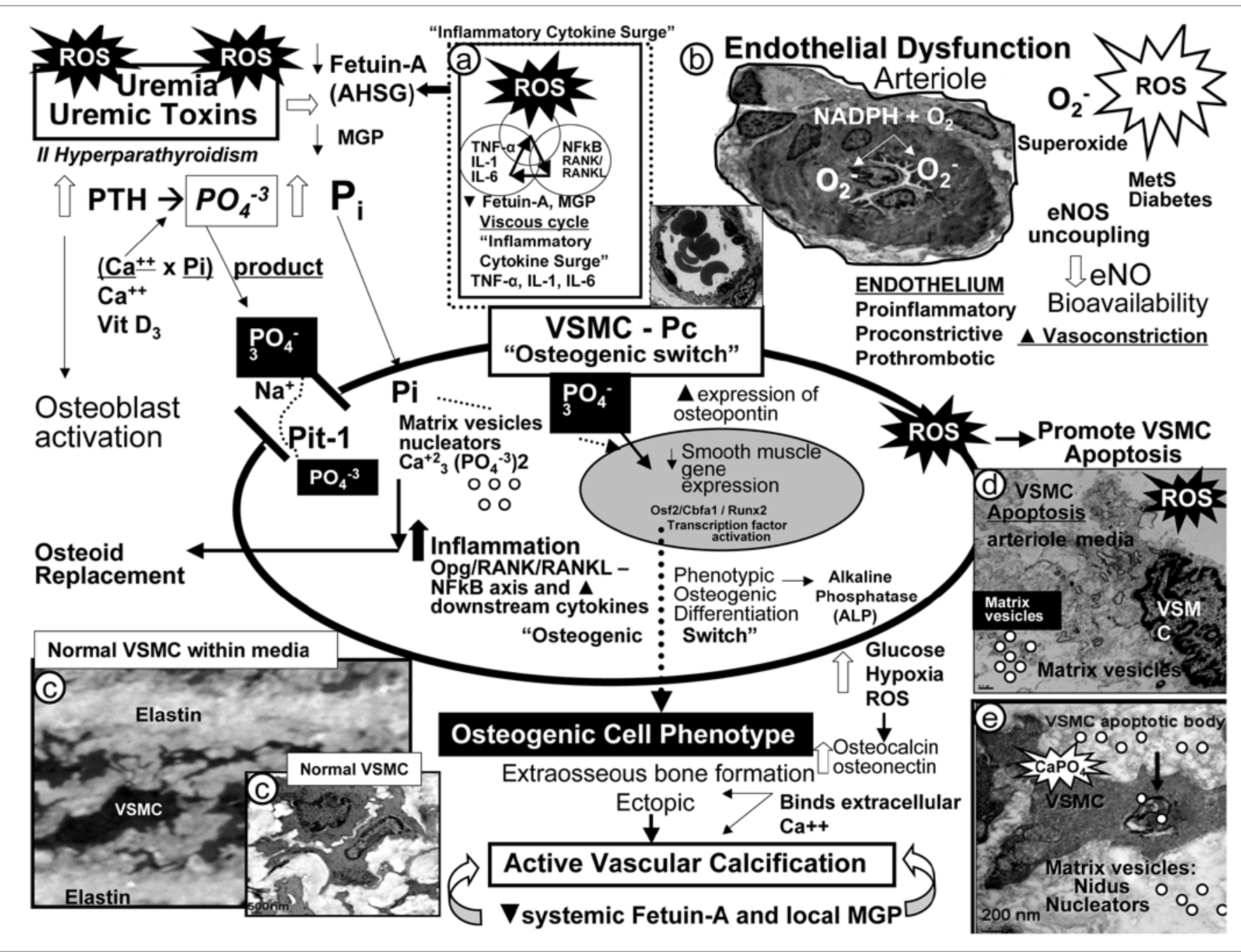

Figure 4. Potential mechanisms involving uremic toxins and reactive oxygen species (ROS) in vascular calcification. Uremic toxins: Increased parathyroid hormone $(\mathrm{PTH})$, phosphorus $(\mathrm{Pi})$ and phosphate $\left(\mathrm{PO}_{4}^{-3}\right)$, calcium, calcium $x$ phosphorus product, vitamin $\mathrm{D}_{3^{\prime}}$ and $\mathrm{ROS}$ significantly contribute to vascular smooth muscle cell (VSMC) and/or pericyte (Pc) differentiation into an osteoblast-like phenotype. Phosphate absorption into these cells is facilitated by the sodium phosphate cotransporter (Pit-1) resulting in an osteogenic switch due to activation of transcription factors: osteoblast-specific cis-acting element (Osf2) - core binding factor alpha1 (Cbfa-1/Runx2). Osteocalcin, osteonectin, bone morphogenic protein-2alpha and alkaline phosphatase (ALP) are inducers of calcification. In contrast, the systemic and local inhibitors of calcification fetuin-A-alpha2-Heremans-Schmid glycoprotein (AHSG) and matrix Gla protein (MGP) are decreased in uremia and calciphylaxis. Further, ROS and inflammatory cytokine surges may contribute to decreased hepatic synthesis of fetuin-A (insert a). Uremic toxins-ROS promote uncoupling of endothelial nitric oxide synthase (eNOS) enzyme via the oxidation of the requisite tetrahydrobiopterin $\left(\mathrm{BH}_{4}\right)$ cofactor and results in the endothelium becoming a net producer of superoxide- $\mathrm{ROS}$ (insert b). Additionally, decreased bioavailable eNO due to eNOS enzyme uncoupling promotes a proinflammatory, proconstrictive, prothrombotic vascular endothelium. ROS are also capable of promoting VSMC apoptosis in the arterial vascular wall (AVW) and when this occurs the matrix vesicles and apoptotic bodies serve as nucleating sites for further calcium deposition in the extracellular matrix of the arteriole media (inserts b-e) (Fig. 1).

Xanthine oxidase, lipooxygenases and cyclooxygenases are capable of generating ROS via both NADPH oxidase dependent and independent pathways, ${ }^{32,33}$ while asymmetrical dimethyl arginine (ADMA) will complete for $\mathrm{L}$-arginine and result in decreased endothelial NO availability independent of eNOS uncoupling. Due to the chronicity of these conditions, the natural occurring antioxidants: catalase, superoxide dismutase and glutathione may become depleted and add to the overall redox stress. Thus, excessive production of ROS may play an important and integral role in the development of CUA/calciphylaxis.
Systemic events, such as surgical stress, promote ROS generation, which activate the nuclear transcription factor NFKB via its receptor RANK and activate the innate wound healing mechanism. The NFKB-ANK/RANKL axis activation, in turn, activates multiple downstream cytokines such as tumor necrosis factor alpha (TNF $\alpha$ ), interleukin (IL-1 and IL-6), which may create a viscous cycle resulting in "inflammatory cytokine surges" (Fig. 4) and may promote the development of CUA/calciphylaxis. These inflammatory cytokine surges and markers such as highly sensitive $\mathrm{C}$ reactive protein (hsCRP) 


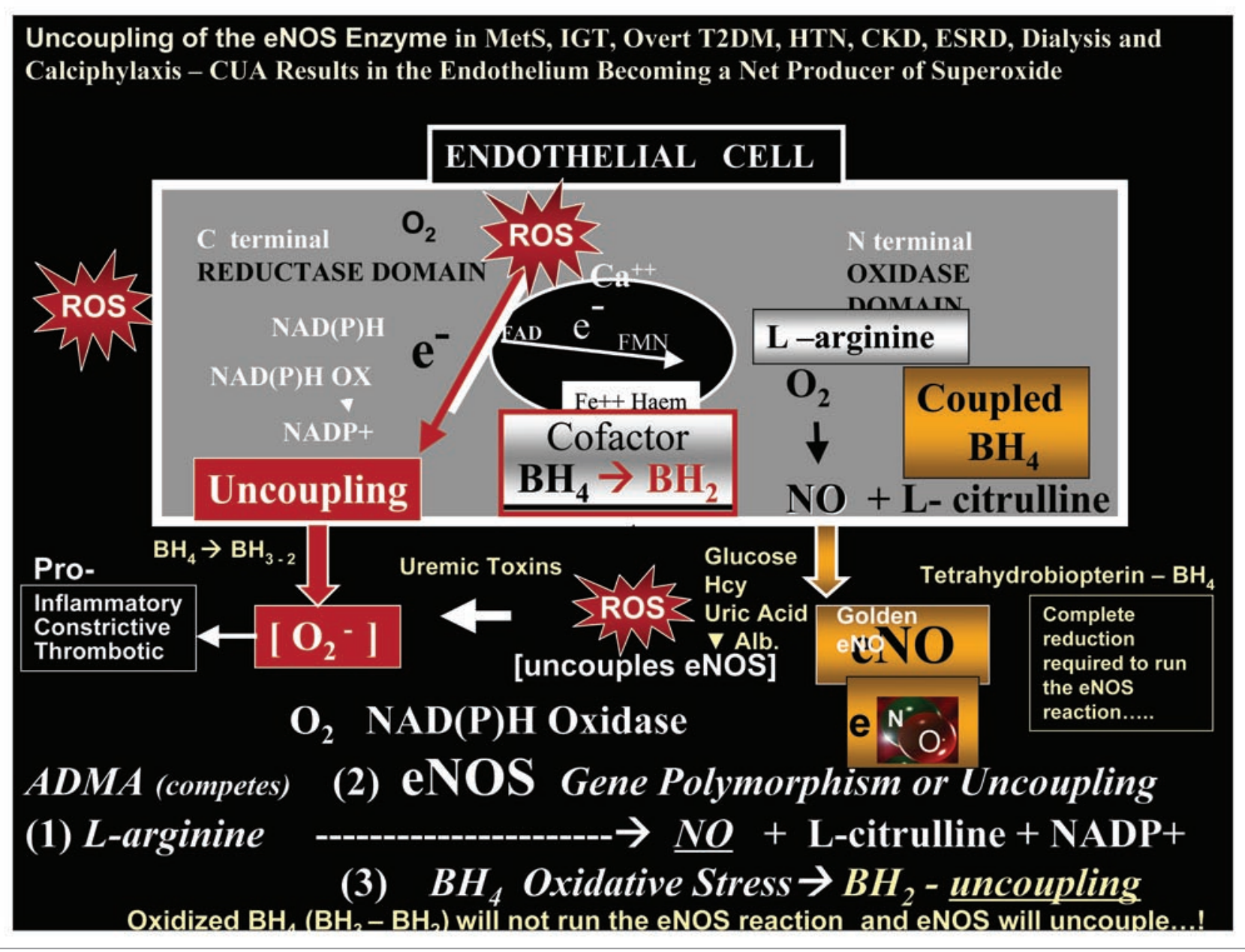

Figure 5. Uncoupling of the eNOS enzyme results in the endothelium becoming a net producer of superoxide. This cartoon depicts many of the significant metabolic events leading to endothelial nitric oxide synthase (eNOS) enzyme uncoupling in the endothelium. Reactive oxygen species (ROS) and their oxidative effects of the requisite cofactor tetrahydrobiopterin $\left(\mathrm{BH}_{4}\right)$ result in eNOS uncoupling. Excessive oxidation of $\mathrm{BH}_{4}$ resulting in the generation of $\mathrm{BH}_{3}$ and $\mathrm{BH}_{2}$ will not run the eNOS reaction to completion. Instead the reaction uncouples and shifts to the $\mathrm{C}$ terminal reductase domain and oxygen reacts with the nicotine adenine dinucleotide phosphorus reduced (NADPH) oxidase enzyme resulting in the generation of superoxide $\left[\mathrm{O}_{2}^{-}\right]$. These dynamic metabolic sequences, involving the uncoupling of the eNOS, reaction result in a proinflammatory, proconstrictive and prothrombotic endothelium, which contributes to endothelial dysfunction. Adapted and expanded with permission. ${ }^{17}$

and elevated sedimentation rates in CKD and ESRD patients on dialysis may decrease both local and systemic calcification inhibitors such as matrix GLA protein (MGP) and fetuin-A respectively. Elevated levels of ROS seem to be playing an important role at each turn of events in vascular calcification in addition to inflammation (Fig. 4). Importantly, ROS are upstream of inflammatory events and play an important role via the activation of NFKB and its receptor in the subsequent downstream activation of inflammatory mediators as well as vascular calcification.

\section{Therapeutic Approaches to Prevent and Treat CUA/Calciphylaxis}

Importantly, the clinician should attempt to reach designated national kidney foundation kidney disease outcomes quality initiative (NFK KDOQI) guidelines in order to bring all abnormal metabolic parameters as close to normal as possible utilizing available dialysis techniques and medications. The following seven therapeutic approaches are introduced randomly.

Calcium and phosphorus strategy. Initially all oral calcium phosphate binders should be replaced with non-calcium phosphate binders (sevelamer, lanthanum carbonate, magnesium carbonate) and all oral calcium supplements should be discontinued. The clinician may also attempt to lower the calcium concentration in the dialysate bath sequentially to $1.0-1.5 \mathrm{mEq} / \mathrm{L}$ as tolerated, while carefully monitoring serum calcium levels. Instead of the standard three days/week dialysis regime, consider increasing dialysis sessions from four to six treatment sessions per week in order to lower the metabolic abnormalities associated with ESRD. ${ }^{6,14,17,34}$

Improvement of hypoxia approach. The beneficial role of hyperbaric oxygen $(\mathrm{HBO})$ therapy has been reported in reviews and multiple trials. ${ }^{1,18,34,35}$ Most of these reports utilize the 
standard of care for reducing the known risk factors involved with the addition of HBO therapy. Mechanisms include counteracting local tissue hypoxia while improving wound healing via increased angiogenesis and fibroblast proliferation with collagen formation to promote wound healing. Additionally, $\mathrm{HBO}$ therapy may increase bactericidal activity in infected wounds by increasing the respiratory oxidative burst from neutrophillic phagocytic NADPH oxidase.

Parathyroid hormone approach. Oral cinacalcet hydrogen chloride to lower intact parathyroid hormone (iPTH) should be considered initially while reserving parathyroidectomy (PTX) for patients with markedly elevated iPTH levels or poor responders to cinacalcet therapy. ${ }^{1,6,14,36}$

PTX with or without autotransplantation is a safe and effective surgical procedure for the treatment of resistant secondary hyperparathyroidism. ${ }^{37}$ Some retrospective studies and case reports evaluating the use of PTX in patients resistant to medical therapy have been positive, ${ }^{38}$ while others have not shown any difference in survival rates with PTX, ${ }^{9}$ therefore, the role of PTX remains controversial. ${ }^{39}$

Wound care approach. In patients with CUA/calciphylaxis the importance of proper wound care and debridement was recently reported to be associated with improved survival in a retrospective study.9 Appropriate local wound care is recommended with gentle wound debridement while avoiding deep or wide surgical debridement and skin grafting. Appropriate sterile dressings should provide a moist environment while removing excessive exudates and be easy to apply and remove in order to reduce surrounding skin trauma. ${ }^{1,6,9,14,17,28,40}$

Anti-inflammatory approach. Antiresorptive bisphosphonates are known to inhibit osteoclastic activity and possess anti-inflammatory actions. These agents have the capability of reducing local macrophage infiltration and activity including decreased secretion of proinflammatory cytokines, thus facilitating the healing of CUA/calciphylaxis lesions. ${ }^{1,6,14,41,42} \mathrm{TNF} \alpha$, IL-6, and C-reactive protein are known positive regulators of vascular calcification and may contribute to medial vascular and tissue calcification in CUA. Therefore, the use of bisphosphonates such as intravenous pamidronate and ibandronate and oral etidronate should be carefully considered in patients failing to respond to other therapeutic modalities. ${ }^{43-46}$

Antithrombotic approach. Low-dose tissue plasminogen activator ( $\mathrm{tPA}$ ) has been reported to be beneficial in a single case report with predominately distal calciphylaxis. ${ }^{47}$ This type of therapy seems logical since many cases of CUA are found to have concurrent obliterative thrombus formation in addition to the obliterative endovascular fibrosis in arterioles. However, further studies are needed in order to properly evaluate this therapy.

Antioxidant approach. The potent antioxidant sodium thiosulfate (STS) has received considerable attention during the past five years for the treatment of CUA/calciphylaxis. ${ }^{6,14,17,48-62}$ Importantly, intravenous STS has recently been shown to prevent vascular calcification in a uremic rat model. ${ }^{63}$ Some leading authors in this exciting field of study have even commented that the most significant progress in the treatment of CUA/calciphylaxis has been the use of STS. ${ }^{64}$
STS has two unpaired electrons (one at the exposed singly bonded oxygen and the other occurring at the exposed singly bonded sulfur moiety of the disulfide bond), which it readily donates to scavenge the unpaired electrons associated with ROS (Fig. 6). ${ }^{17}$ The quenching of ROS associated with the increased oxidative stress may allow recoupling of the uncoupled eNOS enzyme and this effect may well contribute to the rather rapid relief of the subdermal ischemia and the horrific pain associated with CUA/calciphylaxis. ${ }^{6,14,17}$ Additionally, as STS reacts with superoxide and unpaired electrons it may generate the potent naturally occurring antioxidant glutathione (GSH) ${ }^{17}$ Recently, oral STS has been shown to increase depleted hydrogen sulfide $\left(\mathrm{H}_{2} \mathrm{~S}\right)$ in an AV fistula mouse model of congestive heart failure suggesting that STS is capable of reacting via various thiol reactions and transsulfuration enzymes reacting with the endogenous substrate, L-cysteine to generate $\mathrm{H}_{2} \mathrm{~S}$ (Fig. 6). ${ }^{65}$ Some of the positive effects produced by recoupling the uncoupled eNOS enzyme and restoring bioactive endothelial derived $\mathrm{NO}$ include the following: promotion of vasodilation of VSMC and counteracting VSMC proliferation, decreasing platelet adhesiveness and monocytic white blood cells reestablishing the teflon effect of the restored endothelium, promotion of the endothelium's anti-inflammatory, antioxidant, antithrombotic, antiatherosclerotic and anti-fibrotic function via quieting the activity of redox sensitive matrix metalloproteinases (MMPs)..$^{17}$

While the antioxidant effects of STS occur early in the treatment of CUA, the chelating effects take longer; however, over time the chelation effects result in disappearance of subcutaneous and vascular calcification and healing ensues (Figs. 3 and 7). 6,17,46,61,63,64,66 Improved endothelial dysfunction and increased bioavailable $\mathrm{NO}$ via recoupling of the uncoupled eNOS enzyme is currently thought to be playing an important role in the rapid improvement of pain associated with CUA/ calciphylaxis. ${ }^{6,14,17}$ The positive effects of increased bioavailable NO may help to reverse the activation of the endothelium with multiple vesicles and microparticle formation, endothelial denudation and ultrastructure capillary-arteriolar vasoconstriction (Fig. 8).

Side effects of intravenous STS consist of nausea, abdominal cramping, vomiting and/or diarrhea if infused too rapidly (less than one hour). Bone density should be monitored if STS is used long term, since STS was demonstrated to decrease bone strength in the recent rat model preventing vascular calcification. ${ }^{63}$

Most studies support the use of intravenous STS at a dosage of 25 grams (two 12.5 gram vials diluted in $100 \mathrm{cc}$ of normal saline) during the last hour of hemodialysis and some suggest that 12.5 grams per $100 \mathrm{cc}$ of normal saline be used initially over a one hour infusion as a test dose and if tolerated proceed to 25 grams. ${ }^{6,14,48-62,64}$ Additionally, STS has been used with peritoneal dialysis ${ }^{52}$ and in pediatric patients $\left(25 \mathrm{~g} / 1.7 \mathrm{~m}^{2}\right) .{ }^{54}$ The duration of therapy depends on each individual patient; however, current thoughts are that intravenous STS should be used for at least two months beyond complete healing of the skin ulcerations. ${ }^{6,14,17}$ The relief from pain is usually rapid (days to weeks), while healing of skin ulcerations usually require several weeks to months of treatment with longer treatment dependent on original size and 


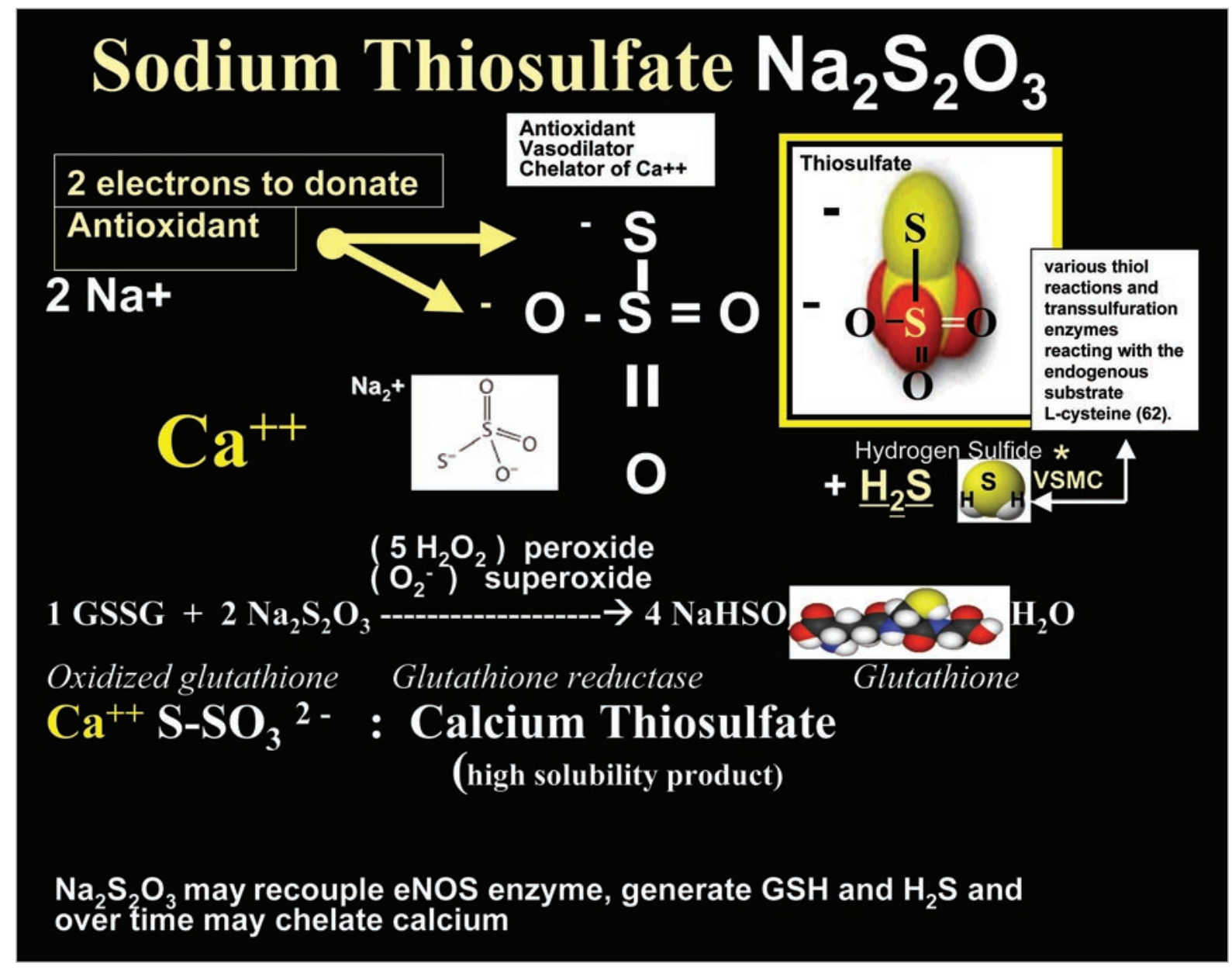

Figure 6. Potential mechanisms of sodium thiosulfate allowing for its antioxidant, vasodilator and chelation properties. This cartoon demonstrates the molecular structure of sodium thiosulfate (STS) and its two readily donated unpaired electrons, which facilitate quenching of unpaired electrons, generation of the antioxidant glutathione $(\mathrm{GSH})$, vasodilator hydrogen sulfide $\left(\mathrm{H}_{2} \mathrm{~S}\right)$, and calcium chelation forming the highly soluble calcium thiosulfate. Adapted with permission. ${ }^{17}$

number of ulcerations. In summary, one could say that the STS story has evolved from Selye to Sulfates.

With each of the therapeutic approaches, it is wise to monitor temperatures daily and aggressively obtain blood cultures should there be any fever or chills suggesting sepsis, as these patients have a weakened immune response and are extremely high-risk for developing sepsis and endocarditis secondary to chronic skin ulcerations. ${ }^{6,14,17}$ Also, it is appropriate to minimize each of the positive regulators of vascular calcification. Special attention should be given to the discontinuation of warfarin, as it has been incriminated in the development of CUA/calciphylaxis due to blocking vitamin K-dependent carboxylation of the matrix GLA protein. ${ }^{17}$

\section{CUA/Calciphylaxis in the Pediatric Population}

The current literature regarding CUA/calciphylaxis and its management in the pediatric population is limited. ${ }^{67}$ Vascular and soft tissue calcification is common in children occurring in up to $60 \%$ in those with ESRD; however, the incidence of CUA is unknown with only 10 case reports identified to date (census date 25 January 2010). ${ }^{54,67-70}$ Previous reviewers have noted the following pertinent findings regarding the pediatric population: Increased risk in males ( $90 \%$ of the cases reported to date) with ESRD and secondary hyperparathyroidism, frequent distal extremity and visceral organ involvement, worse prognosis with acral-distal involvement, and increased resistance to medical treatment compared to the affected adult population. ${ }^{69}$ However, clinicians should keep in mind that with the continuing increase in childhood obesity there may be a changing trend in the future involving more proximal adipose tissue related skin ulceration. There are now four successful outcomes regarding mortality with intravenous STS. ${ }^{54,67}$ Recently, it has been suggested that CUA/calciphylaxis requires early and aggressive intervention with the use of multi-faceted therapeutic approaches as previously described with the recommendation of including conversion from peritoneal dialysis to hemodialysis, intravenous STS infusions, and hyperbaric oxygen therapy. ${ }^{67}$ Appropriate dose adjustments should be made for the pediatric population ${ }^{71}$ and intravenous STS at a dose of $25 \mathrm{~g} / 1.7 \mathrm{~m}^{2}$ diluted in $100 \mathrm{cc}$ of 

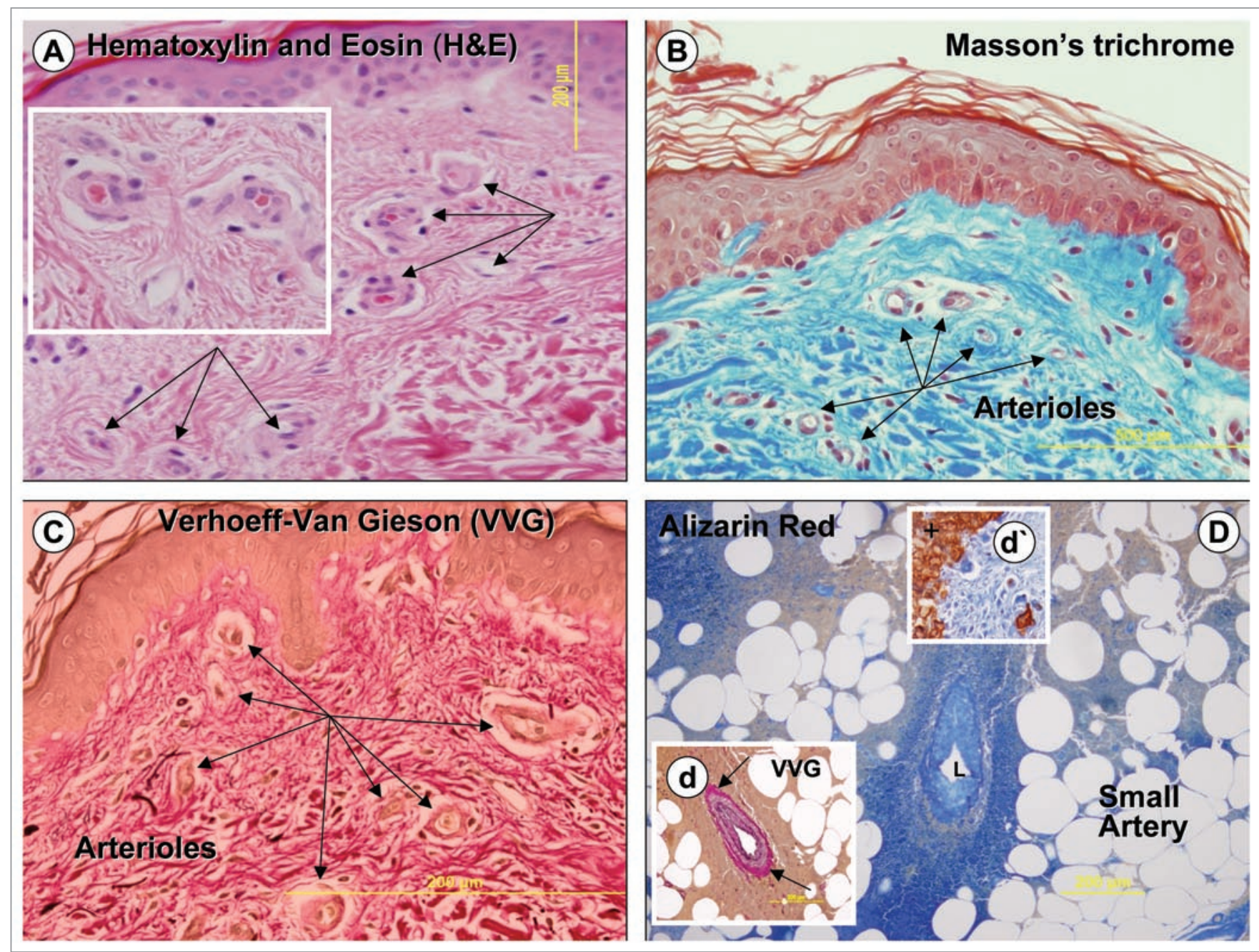

Figure 7. No vascular calcification following four years of intermittent ( 3 times/week) intravenous sodium thiosulfate. These histopathologic figures depict numerous open arterioles (arrows) (A-C) with no evidence of calcific obliterative arteriolopathy in the subdermal interstitium from biopsy of skin adjacent to previously healed ulceration in Figure 3. In (D), note the specific stain for calcium (alizarin red) is negative. Insert (d) demonstrates normal periarteriolar adventitial collagen (arrows), while insert ( $d^{\prime}$ ) depicts the positive control for alizarin red. Concurrently, this same patient as in Figures 2 and 3 did not have any subcutaneous calcifications when evaluated with bone scan (figure not shown).

normal saline infused over one hour after each hemodialysis session three times per week has been recommended (see section on therapeutic approaches). ${ }^{6,54}$

\section{Conclusion}

CKD, ESRD, uremic toxins and dialysis (Fig. 4) result in a metabolic milieu creating the "perfect storm" for the development of accelerated medial vascular calcification and remain a major underlying predisposing factor for the development of CUA/ calciphylaxis. ${ }^{6,14,17,64,72}$

Physiological serum concentrations of calcium and phosphate are several orders of magnitude above their solubility product, which suggests that systemic (fetuin-A) and/or local (MGP) mechanisms are operative in order to prevent extraosseous and medial vascular calcification. While Wilmer and Magro's two stage theory helps to understand this situation, ${ }^{29}$ the exacting factor(s) precipitating CUA remain elusive at this point in time. Similarly, the observation that a large number of patients can share a similar constellation of risk factors and not develop CUA remains unclear. In this review we have suggested that the reduction of inhibitors of calcification, especially fetuin- $A$, as a result of a vicious ROS-inflammatory cytokine surge may be playing an important role for this rapid deposition of calcium with remodeling arteriolar obliterative and/or thrombotic occlusion. Indeed, the liver plays an important role in protein synthesis and it is known that a ROS-cytokine-inflammation axis is capable of inducing the synthesis of innate acute phase reactant proteins such as fibrinogen, serum amyloid $\mathrm{A}$, and $\mathrm{C}$ reactive protein. Concurrently, the ROS-cytokine-inflammation axis is capable of inhibiting the hepatic synthesis of protective antioxidant proteins such as albumin resulting in hypoalbuminemia (a known risk factor for the development of CUA/calciphylaxis, Table 1) and the systemic constitutive inhibitor of vascular calcification, 

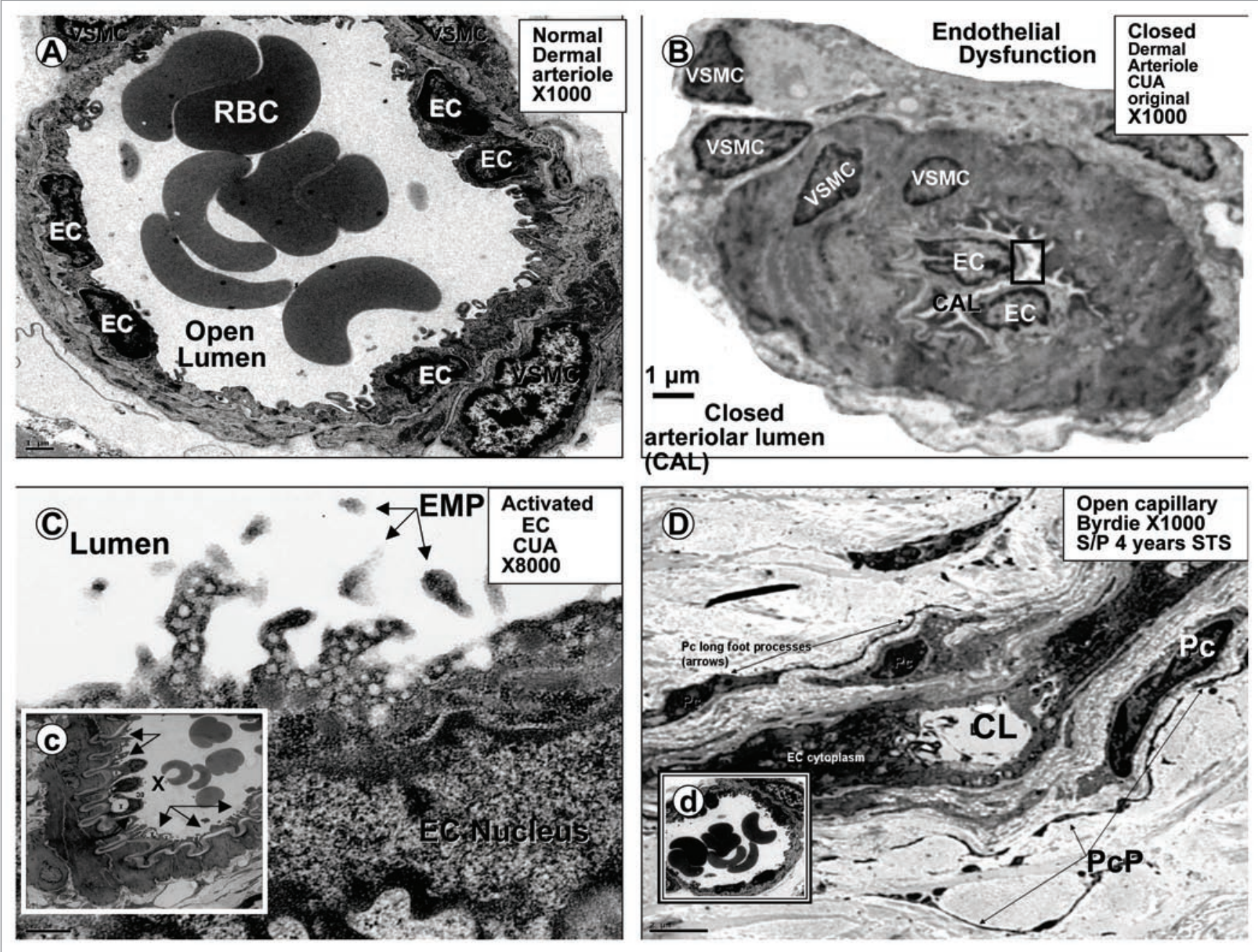

Figure 8. Microcirculation ultrastructure in calcific uremic arteriolopathy. (A) depicts a normal small arteriole (approximately 25-30 $\mu \mathrm{m}$ diameter) with normal lining endothelial cell(s) (EC), and a single layer of supportive vascular smooth muscle cell(s) (VSMC), also note the open lumen with numerous red blood cells (RBC), bar $=1 \mu \mathrm{m}$. (B) (in contrast) demonstrates a closed arteriolar lumen in a small arteriole (approximately 12-15 $\mu \mathrm{m}$ diameter) from a patient's subcutaneous skin ulceration with CUA compatible with endothelial dysfunction, vasoconstriction, and closed arteriolar lumen (CAL), bar $=1 \mu \mathrm{m}$. (C) is a higher magnification of the boxed in region of the endothelium in (B) and may portray an activated endothelium demonstrating multiple cytoplasmic projections containing numerous vesicles, $\mathrm{bar}=0.2 \mu \mathrm{m}$. Additionally, note the free particles in the lumen, which may represent endothelial microparticles (EMP) from the activated endothelium. Insert (c) displays an arteriole with endothelial denudation (arrows) and abnormal ballooning of ECs with vacuole formation from same patient, bar $=2 \mu \mathrm{m}$. (D) depicts an open capillary lumen (CL) in the subcutaneous tissue of skin biopsy adjacent to previous skin ulceration due to CUA (four years earlier, Fig. 3) treated with sodium thiosulfate (STS) for 4 years. Also note the normal appearing pericytes (Pc) and multiple pericyte processes (PcP), which are restored and known to be very sensitive to oxidative stress. Insert (d) portrays a normal open arteriole suggesting that STS may promote both capillary and arteriolar vasodilation.

fetuin-A (a negative acute phase protein). ${ }^{73,74}$ While this concept is not proven and currently remains speculative, it may help to provide a better understanding how the puzzling-post surgical patients (including those who are post renal transplant and post parathyroidectomy) develop this devastating clinical condition. This speculative concept may also help to explain why some and not others with similar risk factor profiles and similar laboratory values develop CUA/calciphylaxis and others do not. Hopefully, the new fetuin-A knockout mouse model will aid in a better understanding of the role of fetuin- $A$ and its relationship to CUA/calciphylaxis. Also, future experiments that measure fetuin-A in those patients treated with and without sodium thiosulfate may be of great value and serve as future biomarkers for the early identification of CUA/calciphylaxis.

Biomarkers, in addition to oxidant stress and inflammation that may be considered in the future, may relate to an activated, dysfunctional or damaged-apoptotic endothelium and liberation of endothelial microparticles (EMP) in CUA/calciphylaxis (Fig. 8). EMP and multiple activated endothelial biomarkers have been described including E-selectin, intercellular adhesion molecule 1 (I-CAM-1), vascular cell adhesion molecule 1 (V-CAM-1), and von Willebrand factor (vWF). ${ }^{75}$ Interestingly, a recent report has demonstrated that hypoxia is capable of inducing both V-CAM-1 and a novel biomarker (S100A12), a calcium 
Table 2. Calcific uremic arteriolopathy/calciphylaxis registries

Germany: Calciphylaxie Register, International Collaborative Calciphylaxis Network

www.calciphylaxie-register.ukaachen.de/ www.calciphylaxie-register.klinikum-coburg.de/ www.calciphylaxie.de/

US: Calciphylaxis Registry, KU Medical Center, University of Kansas

www2.kumc.edu/calciphylaxisregistry/

UK: UK Calciphylaxis Registry, International Collaborative Calciphylaxis Network

www.calciphylaxis.org.uk/

binding protein belonging to the $\$ 100$ family, may function as biomarkers ${ }^{76,77}$ and could potentially contribute to the early identification of CUA/calciphylaxis prior to skin ulceration and possibly monitor therapy. Additionally, future refinement of endothelial microparticles assays could provide new vistas both for evaluating and monitoring therapeutic approaches in CUA/ calciphylaxis.

Each of the seven therapeutic approaches (except the wound care approach) offers the potential to reduce metabolic abnormalities associated with CKD and ESRD requiring renal replacement therapy. While each approach is very important, it may be noted that the antioxidant approach with STS is directly or indirectly involved in five of the seven therapeutic approaches and may represent an emerging component of most therapeutic strategies to treat CUA. ${ }^{6,14,17,30,48-62}$ Not only is STS a potent antioxidant but also an integral component of the hypoxia, anti-inflammatory and antithrombotic approaches. Additionally, through its more delayed calcium chelation properties, it may be involved with the calcium and phosphorous approach.

Currently, there are no randomized prospective controlled clinical trials available upon which we can base our plan of therapy and some have stated that it is unlikely that such trials will be conducted. ${ }^{18}$ Therefore, CUA/calciphylaxis registries that record various therapeutic approaches would be extremely useful to identify further risk factors, biomarkers, and potential abnormalities to gain a better insight into its pathogenesis, early diagnosis, and treatment. Furthermore, monitoring and creating evidence based guidelines for future treatment modalities in contrast to empirically based regimes based on case reports and reviews as recommended in a recent publication by Schlieper et al. may be of considerable benefit. ${ }^{78}$ Current web based registries have been established in Germany, US and UK (Table 2). We strongly urge clinicians treating patients with CUA/calciphylaxis to enter their patient's data and submit specimens into these registries when appropriate.

When patients present with risk factors for CUA/calciphylaxis (Table 1) complaining of dermal pain and have the associated skin changes of livedo reticularis or painful subcutaneous nodules or plaques, we as clinicians should be highly suspicious for the future development of skin ulcerations. Since it is these very non-healing skin ulcerations that place our patients at such high risk for sepsis and increased mortality, we should not wait for the development of skin ulcerations in order to aggressively treat the underlying metabolic abnormalities that are known to be risk factors for the development of CUA/calciphylaxis.

\section{Acknowledgements}

Authors wish to thank James R. Sowers, Director Cosmopolitan International Diabetes and Cardiovascular Center of the University of Missouri, School of Medicine; Columbia, Missouri for providing editorial assistance. Funding support has been provided by National Kidney Foundation Nephrology Fellow Basic Science Grant (K.M.S.).

\section{References}

1. Coates T, Kirkland GS, Dymock RB, Murphy BF Brealey JK, Mathew TH, et al. Cutaneous necrosis from calcific uremic arteriolopathy. Am J Kidney Dis 1998; 32:384-91.

2. Pollock B, Cunliffe W, Merchant W. Calciphylaxis in the absence of renal failure. Clin Exp Dermatol 2000; 25:389.

3. Goyal S, Huhn K, Provost T. Calciphylaxis in a patient without renal failure or elevated parathyroid hormone: the possible aetiological role of chemotherapy. $\mathrm{Br} \mathrm{J}$ Dermatol 2000; 143:1087-90.

4. NigwekarSU, Wolf M, Sterns RH, Hix JK. Calciphylaxis from nonuremic causes: a systematic review. Clin J Am Soc Nephrol 2008; 3:1139-43.

5. Don BR, Chin AL. A strategy for the treatment of calcific uremic arteriolopathy (calciphylaxis) employing a combination of therapies. Clin Nephrol 2003; 59:46370 .

6. Hayden MR, Goldsmith D, Sowers JR, Khanna R. Calciphylaxis: calcific uremic arteriolopathy and the emerging role of sodium thiosulfate. Int Urol Nephrol 2008; 40:443-51.

7. Angelis M, Wong LL, Myers SA, Wong LM. Calciphylaxis in patients on hemodialysis: a prevalence study. Surgery 1997; 122:1083-9.

8. Fine A, Zacharias J. Calciphylaxis is usually nonulcerating: risk factors, outcome and therapy. Kidney Int 2002; 61:2210-7.
9. Weenig RH, Sewell LD, Davis MD, McCarthy JT, Pittelkow MR. Calciphylaxis: natural history, risk factor analysis, and outcome. J Am Acad Dermatol 2007; 56:569-79.

10. Bleyer AJ, Choi M, Igwemezie B, de la Torre E, White WL. A case control study of proximal calciphylaxis. Am J Kidney Dis 1998; 32:376-83.

11. Ahmed S, O'Neill KD, Hood AF, Evan AP, Moe SM. Calciphylaxis is associated with hyperphosphatemia and increased osteopontin expression by vascular smooth muscle cells. Am J Kidney Dis 2001; 37:1267-76.

12. Ketteler M, Biggar PH, Brandenburg VM, Schlieper G, Westenfeld R, Floege J. Epidemiology, pathophysiology, and therapy of calciphylaxis. Dtsch Arztebl 2007; 104:3481-5.

13. Mazhar AR, Johnson RJ, Gillen D, Stivelman JC, Ryan MJ, Davis CL, et al. Risk factors and mortality associated with calciphylaxis in end-stage renal disease: Kidney Int 2001; 60:324-32.

14. Hayden MR. Calciphylaxis and the cardiometabolic syndrome: the emerging role of sodium thiosulfate as a novel treatment option. J Cardiometab Syndr 2008; 3:55-9.

15. Selye H. Calcihylaxis. Chicago, University of Chicago Press 1962.

16. Moe SM, Chen NX. Mechanisms of vascular calcification in chronic kidney disease. J Am Soc Nephrol 2008; 23:213-6.
17. Hayden MR, Tyagi SC, Kolb L, Sowers JR, Khanna R. Vascular ossification-calcification in metabolic syndrome, type 2 diabetes mellitus, chronic kidney disease and calciphylaxis-calcific uremic arteriolopathy: the emerging role of sodium thiosulfate. Cardiovasc Diabetol 2005; 4:4.

18. Rogers NM, Teubner DJ, Coates PT. Calcific uremic arteriolopathy: advances in pathogenesis and treatment. Semin Dial 2007; 20:150-7.

19. Wozney JM, Rosen V, Celeste AJ, Mitsock LM, Whitters MJ, Kriz RW. Novel regulators of bone formation: molecular clones and activities. Science 1998; 242:1528-34.

20. Feng JQ, Xing L, Zhang JH, Xhao M, Horn D, Chan J, et al. NFKappaB specifically activates BMP-2 gene expression in growth plate chnondrocytes in vivo and in a chondrocyte cell line in vitro. J Biol Chem 2003; 278:29130-5.

21. Schafer C, Heiss A, Schwarz A, Westenfeld R, Ketteler $M$, Floege J, et al. The serum protein $\alpha_{2}$-HeremansSchmide glycoprotein/fetuin-A is a systemically acting inhibitor of ectopic calcification. J Clin Invest 2003; 112:357-66

22. Ketteler M, Bongartz P, Westenfeld R, Hildberge JE, Mahnken AH, Bohm R, et al. Association of low Fetuin-A (AHSG) concentrations in serum with cardiovascular mortality in patients on dialysis; a cross-sectional study. Lancet 2003; 361:827-33. 
23. Kiechi S, Werner P, Knoflach M, Furtner M, Willeit J, Schett G. The osteoprotegerin/RANK/RANKL system a bone key to vascular disease. Expert Rev Cardiovasc Ther 2006; 4:801-11.

24. Hayden MR, Stump CS, Sowers JR. Organ involvement in the cardiometabolic syndrome. J Cardiometab Syndr 2006; 1:16-24.

25. Bloomer RJ, Fisher-Wellman KH. Systemic oxidative stress is increased to a greater degree in young obese women following consumption of high fat meal. Oxid Med Cell Longev 2009; 2:19-25.

26. Wu SY, Zhang BH, Pan CS, Jiang HF, Pang YZ, Tang CS. Endothelin-1 is a potent regulator in vivo in vascular calcification and in vitro in calcification of vascular smooth muscle cells. Peptides 2003; 24:1149-56.

27. Yang H, Curinga G, Giachelli CM. Elevated extracellular calcium levels induce smooth muscle cell matrix mineralization in vitro. Kidney Int 2004; 66:2293-9.

28. Griethe W, Schmitt R, Jurgensen JS, Bachmann S, Eckardt KU, Schindler R. Bone morphogenic protein- 4 expression in vascular lesions of calciphylaxis: Journal Nephrol 2003; 16:728-32.

29. Wilmer WA, Magro CM. Calciphylaxis: emerging concepts in prevention, diagnosis and treatment. Semin Dial 2002; 15:172-86.

30. Hayden MR, Kolb LG, Khanna R. Calciphylaxis and the cardiometabolic syndrome. J Cardiometab Syndr 2006; 1:76-9.

31. Hayden MR, Tyagi SC. Intimal redox stress: accelerated atherosclerosis in metabolic syndrome and type 2 diabetes mellitus: Atheroscleroapathy. Cardiovasc Diabetol 2002; 1:3.

32. Hayden MR, Whaley-Connell A, Sowers JR. Renal redox stress and remodeling in metabolic syndrome, type 2 diabetes mellitus and diabetic nephropathy: paying homage to the podocyte. Am J Nephrol 2005; 25:553-69.

33. Nistala R, Whaley-Connell A, Sowers JR. Redox control of renal function and hypertension. Antioxid Redox Signal 2008; 10:2047-89.

34. Basile C, Montanaro A, Masi M, Pati G, DeMaio P, Gismondi A. Hyperbaric oxygen therapy for calcific uremic arteriolopathy (calciphylaxis): a case series. J Nephrol 2002; 15:676-80.

35. Arenas MD, Gil MT, Gutierrez MD, Malek T, Moledous A, Salinas A, et al. Management of calcific uremic arteriolopathy (calciphylaxis) with a combination of treatments, including hyperbaric oxygen therapy. Clin Nephrol 2008; 70:261-4.

36. Velasco N, MacGregor M, Innes A, Mackay I. Successful treatment of calciphylaxis with cinacalcet-an alternative to parathyroidectomy? Nephrol Dial Transplant 2006; 21:1999-2004.

37. Drakopoulos S, Koukoulaki M, Apostolou T, Pistolas D, Balaska K, Gavrill S, et al. Total parathyroidectomy without autotransplantation in dialysis patients and renal transplant recipients, long-term foll-up evaluation. Am J Surg 2009; 198:178-83.

38. Girotto JA, Harmon JW, Ratner LE, Nichol TL, Wong L, Chen H. Parathyroidectomy promotes wound healing and prolongs survival in patients with calciphylaxis from secondary hyperparathyroidism. Surgery 2001, 130:645-50.

39. Bazari H, Jaff MR, Mannstadt M, Yan S. Case 7-2007. A 59 year old woman with diabetic renal disease and nonhealing skin ulcers. N Engl J Med 2007; 356:1049-57.

40. Bradley M, Cullum N, Nelson EA, Petticrew M, Sheldon T, Torgerson D. Systematic reviews of wound care management: (2). Dressings and topical agents used in the healing of chronic wounds. Health Technol Assess 1999; 3:1-35.

41. Cecchini MG, Felix R, Fleisch H, Cooper PH. Effects of bisphosphonates on proliferation and viability of mouse bone marrow derived macrophages. J Bone Miner Res 1987; 2:135-42.
42. Pennanen N, Lapinjoki S, Urtti A, Monkkonen J. Effect of liposomal and free bisphosphonates on ILbeta, IL-6 and TNFalpha secretion from RAW 264 cells in vitro. Pharm Res 1995; 12:916-22.

43. Phanish MK, Kallarackal G, Rayanan R, Lawson TM, Baboolal K. Tumoral calcinosis associated with pyrexia and systemic inflammatory response in a haemodialysis patient: successful treatment using intravenous pamidronate. Nephrol Dial Transplant 2000; 15:1691 3.

44. Monney P, Nguyen QV, Perroud H, Descombes E. Rapid improvement of calciphylaxis after intravenous pamidronate therapy in a patient with chronic renal failure. Nephrol Dial Transplant 2004; 19:2130-2.

45. Musso CG, Enz PA, Guelman R, Mombelli C, Imperiali N, Plantalech L, et al. Non-ulcerating calcific uremic arteriolopathy skin lesion treated successfully with intravenous ibandronate. Perit Dial Int 2006, 26:717-8.

46. Shiraishi N, Kitamura K, Miyoshi T, Adachi M, Kohd Y, Nonoguchi H, et al. Successful treatment of a patient with severe calcific uremic arteriolopathy (calciphylaxis) by etidronate sodium. Am J Kidney Dis 2006; 48:151-4.

47. Sewell LD, Weenig RH, Davis MDP, McEvoy MT, Pittelkow MR. Low dose tissue plasminogen activator for calciphylaxis. Arch Dermatol 2004; 140:1043-8.

48. Cicone JS, Petronis JB, Embert CD, Spector DA. Successful management of calciphylaxis with intravenous sodium thiosulfate. Am J Kidney Dis 2004; 43:1104-8.

49. Guerra G, Shah RC, Ross EA. Rapid resolution of calciphylaxis with intravenous sodium thiosulphate and continuous venovenous haemofiltration using low calcium replacement fluid: case report. Nephrol Dial Transplant 2005; 20:1260-2.

50. Brucculeri M, Cheigh J, Bauer G, Serur D. Long-term intravenous sodium thiosulfate in the treatment of a patient with calciphylaxis. Semin Dial 2005; 18:431

51. Meissner M, Bauer R, Beier C, Betz C, Wolter M, Kaufmann R, et al. Sodium thiosulphate as a promising therapeutic option to treat calciphylaxis. Dermatology 2006; 212:373-6.

52. Mataic D, Bastani B. Intraperitoneal sodium thiosulphate for the treatment of calciphylaxis. Ren Fail 2006; 28:361-3.

53. Tokashiki K, Ishida A, Kouchi M, Ishihara S, Tomiyama N, Kohagura K, et al. Successful management of critical limb ischemia with intravenous sodium thiosulphate in a chronic hemodialysis patient. Clin Nephrol 2006; 66:140-3.

54. Araya CE, Fennell RS, Neiberger RE, Dharnidharka VR. Sodium thiosulfate treatment for calcific uremic arteriolopathy in children and young adults. Clin J Am Soc Nephrol 2006; 1:1161-6.

55. Baker BL, Fitzgibbons CA, Buescher LS. Calciphylaxis responding to sodium thiosulfate therapy. Arch Dermatol 2007; 143:269-70.

56. Ackermann F, Levy A, Daugas E, Schartz N, Riaux A, Derancourt C, et al. Sodium thiosulfate as first-line treatment for calciphylaxis. Arch Dermatol 2007; 143:1336-7.

57. Subramaniam K, Wallace H, Sinniah R, Saker B. Complete resolution of recurrent calciphylaxis with long-term intravenous sodium thiosulfate. Australas J Dermatol 2008; 49:30-4

58. Soni S, Leslie WD. Bone scan findings in metastatic calcification from calciphylaxis. Clin Nucl Med 2008; 33:502-4.

59. Raymond CB, Wazny LD. Sodium thiosulfate, bisphonates and cinacalcet for treatment of calciphylaxis. Am J Health Syst Pharm 2008; 65:1419-29.
60. Tindi A, Gauray K, Panda M. Non-healing painful ulcers in a patient with chronic kidney disease and role of sodium thiosulfate. A case report. Cases J 2008; $1: 178$.

61. Kyritsis I, Gombou A, Griveas I, Agroyannis I, Retsa K, Agroyannis B. Combination of sodium, cinacalcet and paricaicitol in the treatment of calciphylaxis with hyperparathyroidism. Int J Artif Organs 2008; 31:742-4.

62. Hackett BC, McAleer MA, Sheehan G, Powell FC, O'Donnell BF. Calciphylaxis in a patient with normal renal function: response to treatment with sodium thiosulfate. Clin Exp Dermatol 2009; 34:39-42.

63. Pasch A, Schaffner T, Huynh-Do U, Frey BM, Frey FJ, Farese S. Sodium thiosulfate prevents vascular calcifications in uremic rats. Kidney Int 2008; 74:1444-53.

64. Rogers NM, Coates PT. Calcific uraemic arteriolopathy: an update. Curr Opin Nephrol Hypertens 2008; 17:639-40

65. Sen U, Vacek TP, Hughes WM, Kumar M, Moshal KS, Tyagi N, et al. Cardioprotective role of sodium thiosulfate on chronic heart failure by modulating endogenous $\mathrm{H}_{2} \mathrm{~S}$ generation. Pharmacology 2008; 82:201-13.

66. Yatzidis H. Successful sodium thiosulphate treatment for recurrent calcium urolithiasis. Clin Nephrol 1985; 23:63-7.

67. Amin N, Gonzalez E, Lieber M, Salusky IB, Zaritsky JJ. Successful treatment of calcific uremic arteriolopathy in a pediatric dialysis patient. Pediatr Nephrol 2010; 25:357-62.

68. Bakkalogu SA, Dursun I, Kaya A, Soylemezoglu O, Hasanoglu E, Buyan N. Digital calciphylaxis progressing to amputation in a child on continuous ambulatory peritoneal dialysis. Ann Trop Paediatr 2007; 27:149-52.

69. Feng J, Gohara M, Lazova R, Antaya RJ. Fatal childhood calciphylaxis in a 10-year-old and literature review. Pediatr Dermatol 2006; 23:266-72.

70. Imam AA, Mattoo TK, Kapur G, Bloom DA, Valentini RP. Calciphylaxis in pediatric end-stage renal disease. Pediatr Nephrol 2005; 20:1776-80.

71. Sanchez CP. Secondary hyperparathyroidism in children with chronic renal failure: pathogenesis and treatment. Paediatr Drugs 2003; 5:763-76.

72. Towler DA. Vascular calcification in ESRD: Another cloud appears in the perfect storm-but highlights a silver lining? Kidney Int 2004; 66:2467-8.

73. Lebreton JP, Joisel F, Raoult JP, Lannuzel B, Rogez JP, Humbert G. Serum concentration of human alpha $2 \mathrm{HS}$ glycoprotein during the inflammatory process: evidence that alpha2 HS glycoprotein is a negative acute-phase reactant. J Clin Invest 1979; 64:1118-29.

74. Westenfeld R, Schafer C, Smeets R, Brandenburg VM, Floege J, Ketteler M, et al. Fetuin-A (AHSG) prevents extraosseous calcification induced by uremia and phosphate challenge in mice. Nephrol Dial Transplant 2007; 22:1537-46.

75. Horstman LL, Jy W, Jimenez JJ, Ahn YS. Endothelia microparticles as markers of endothelial dysfunction. Front Biosci 2004; 9:1118-35.

76. Maiese K. Marking the onset of oxidative stress: Biomarkers and novel strategies. Oxid Med Cell Longev 2009; 2:1.

77. Vince RV, Chrismas B, Midgley AW, McNaughton LR, Madden LA. Hypoxia mediated release of endothelial microparticles and increased association of $\mathrm{S} 100 \mathrm{~A} 12$ with circulating neutrophils. Oxid Med Cell Longev 2009; 2:2-6.

78. Schlieper G, Brandenburg V, Ketteler M, Floege J. Sodium thiosulfate in the treatment of calcific uremic arteriolopathy. Nat Rev Nephrol 2009; 5:539-43. 


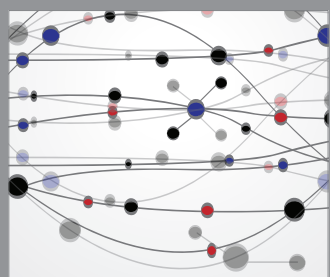

The Scientific World Journal
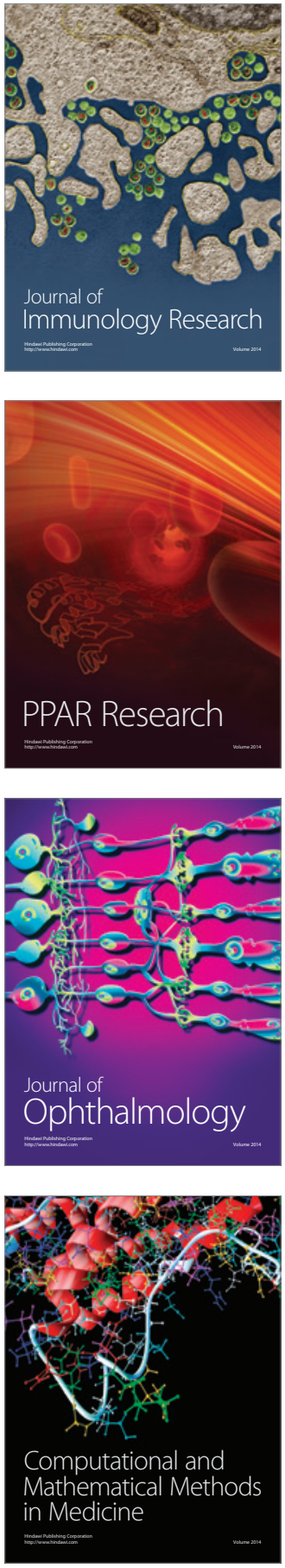

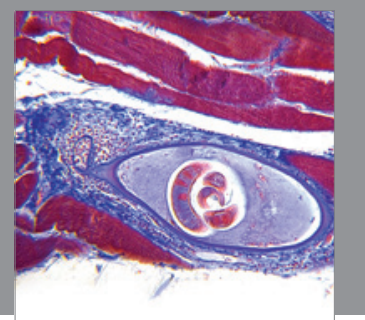

Gastroenterology

Research and Practice
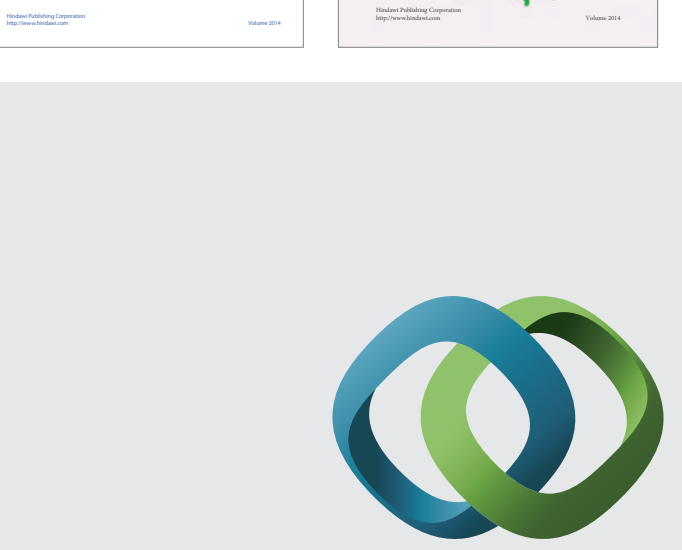

\section{Hindawi}

Submit your manuscripts at

http://www.hindawi.com
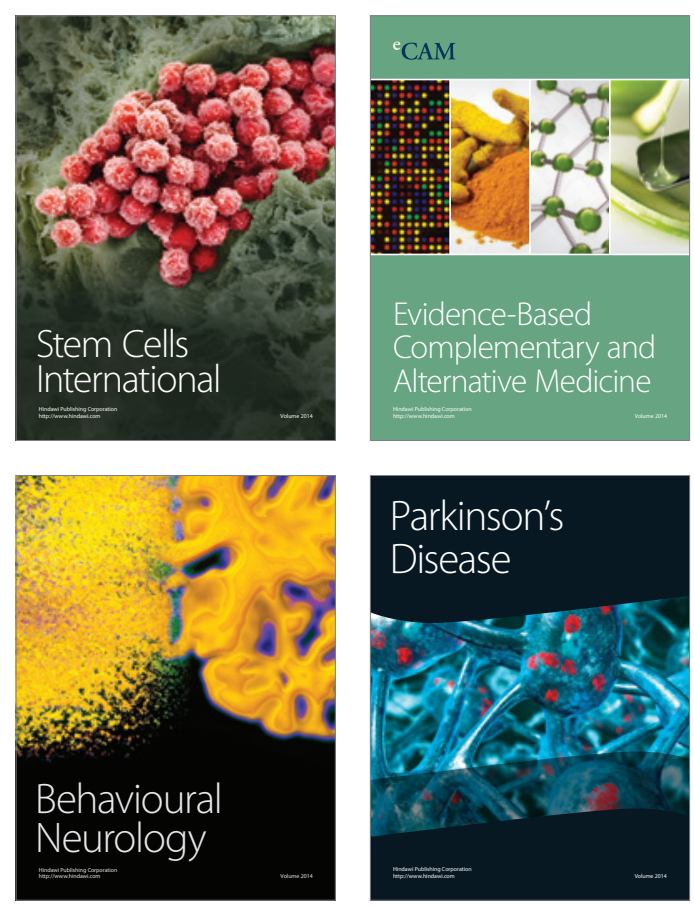

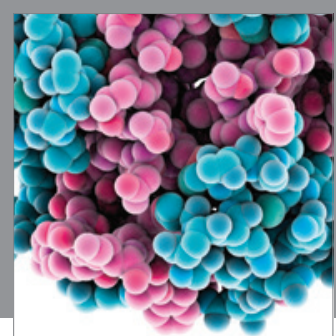

Journal of
Diabetes Research

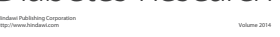

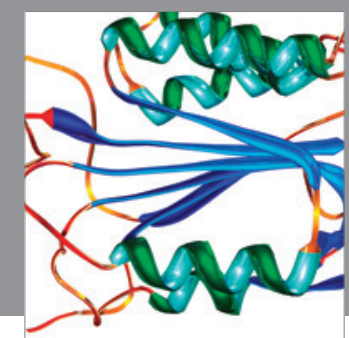

Disease Markers
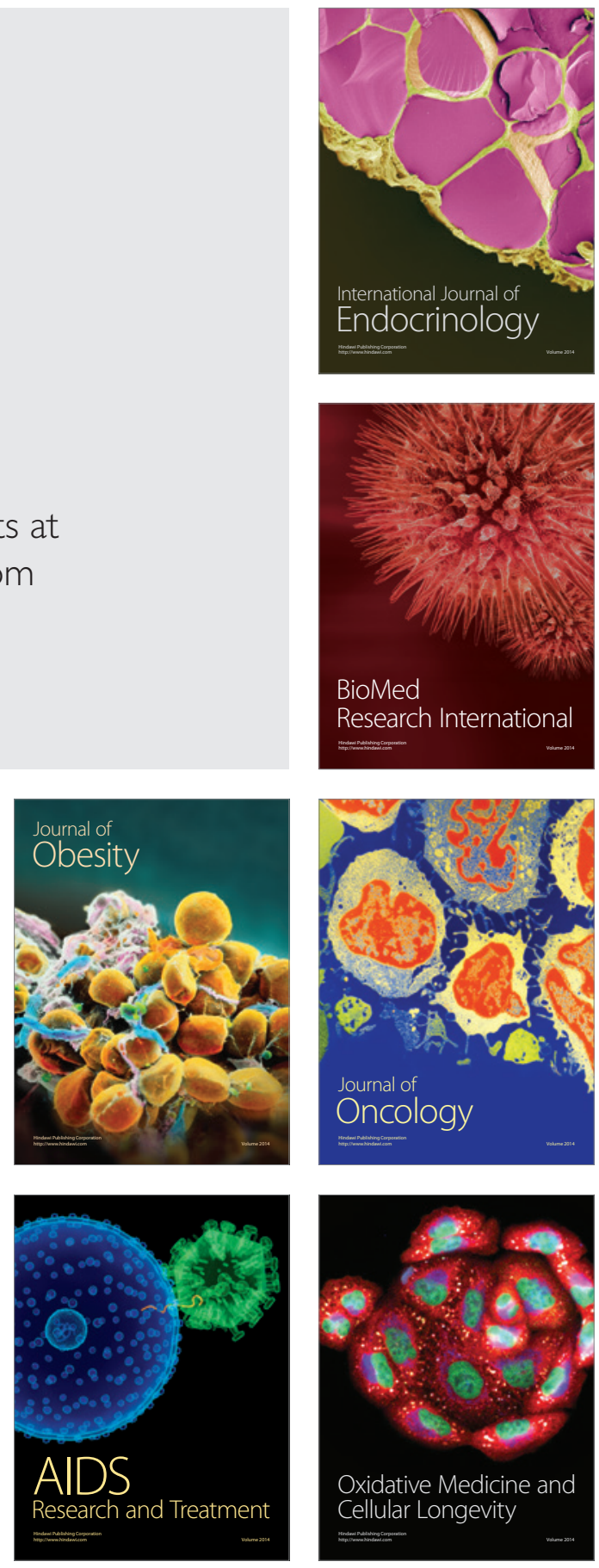